\title{
Pyrethroid residues on tropical soil of an Indonesian tea plantation: analytical method development, monitoring, and risk assessment
}

\author{
Miranti Ariyani ${ }^{1 *}$ D, Mariska Margaret Pitoi ${ }^{1}$, Tiny Agustini Koesmawati ${ }^{1,2}$, Hilman Maulana $^{3}$, Een Sri Endah ${ }^{1}$ and \\ Retno Yusiasih ${ }^{1}$
}

\begin{abstract}
Despite their massive application in tea plantation, synthetic pyrethroids had never been detected in tropical soils of tea plantation thus their risk has never been assessed. This research reported the detection of synthetic pyrethroids in tea plantation and assessed their aquatic ecotoxicological risk. A simplified analytical method based on the application of a miniaturized sample, solvent, and efficient ultra-sonic assisted extraction was developed for the determination of pyrethroids in the soil. The method was validated with the result of all parameters (recovery, $\%$ relative standard deviations, linearity, limit of detection (LoD), and matrix effect) met the acceptance limits suggested by European Commission guideline, thus deemed acceptable for the assessment of pyrethroids in tropical soil of tea plantation during the wet and dry season. Of the five synthetic pyrethroids, only permethrin was detected in both wet and dry seasons $\left(<\mathrm{LOD}-0.36 \mathrm{\mu g} \mathrm{g}^{-1}\right)$, whereas deltamethrin was detected only in wet season $\left(<\mathrm{LoD}-0.12 \mathrm{\mu g} \mathrm{g}^{-1}\right)$. Scanning electron microscopy with energy-dispersive $X$-ray spectrometry and $X$-ray diffraction revealed that the soil constituted by various soil minerals made permethrin more likely to persist than deltamethrin. Aquatic ecotoxicological risk assessment was performed on the basis of comparison between the maximum equilibrium concentration expected in water $\left(E C E W_{\text {max }}\right)$ value and lethal concentration $\left(L_{50}\right)$ of pyrethroids exposure for aquatic species (algae, crustacean, and fish) inhabiting the Upper Citarum River. The ECEW $W_{\text {max }}$ value for the present condition was lower than $L C_{50}$ for all examined species, indicating that the highlevel contamination in the future should have posed a high risk for all aquatic species based on their $L C_{50}$.
\end{abstract}

Keywords: Pyrethroid, Monitoring, Tea plantation, Risk assessment, Green analytical chemistry

\section{Introduction}

Over the last four decades, pyrethroids have been commonly used worldwide as pesticides in both domestic and agricultural environments [1]. Pyrethroids are preferred over highly toxic organophosphorus and organochlorine pesticides because of their lower toxicity to human compared to the last two but still lethal to

\footnotetext{
* Correspondence: miranti.ariyani@gmail.com

${ }^{1}$ Research Unit for Clean Technology, Indonesian Institute of Sciences, Bandung 40135, Indonesia

Full list of author information is available at the end of the article
}

targeted pests even at low concentrations [2]. At present, however, pyrethroids are emerging pollutants due to their ecotoxicological effects on aquatic systems even at extremely low concentrations [3].

Long-term and repeated application of synthetic pyrethroids during agricultural cultivation may contaminate the environment through leaching and runoff. Numerous studies have reported the presence of synthetic pyrethroids such as bifenthrin, cyfluthrin, permethrin, cypermethrin, deltamethrin, and lambda-cyhalothrin in several rivers in urban and agricultural regions [4-6].

(c) The Author(s). 2020 Open Access This article is licensed under a Creative Commons Attribution 4.0 International License, which permits use, sharing, adaptation, distribution and reproduction in any medium or format, as long as you give

appropriate credit to the original author(s) and the source, provide a link to the Creative Commons licence, and indicate if changes were made. The images or other third party material in this article are included in the article's Creative Commons licence, unless indicated otherwise in a credit line to the material. If material is not included in the article's Creative Commons licence and your intended use is not permitted by statutory regulation or exceeds the permitted use, you will need to obtain permission directly from the copyright holder. To view a copy of this licence, visit http://creativecommons.org/licenses/by/4.0/. 
Soil is a well-known terrestrial reservoir of pesticides and other persistent contaminants. Due to their higher affinity for organic carbon and clay in the soil, pyrethroids persist longer in the soil and sediments (up to 1 yr) despite their shorter half-life than other classes of pesticides [7]. Moreover, under anaerobic environments, the mobility and persistence of pyrethroids are lower (with an average half-life of up to $619 \mathrm{~d}$ ) than those of other types of pesticides [8].

Furthermore, pyrethroids pose risks to humans through the food chain and direct contact because of their presence in aquatic organisms and surface water. Previous studies have demonstrated the toxicity of synthetic pyrethroids in aquatic organism, with a very low lethal concentration $\left(\mathrm{LC}_{50}\right)$ of $<1 \mathrm{ppb}[4,9,10]$. Moreover, the International Agency for Research on Cancer and World Health Organization (WHO) have classified pyrethroids as non-carcinogens and moderately hazardous pesticides [11]. WHO and the European Union (EU) have recommended that the maximum concentrations of permethrin and individual pesticides in drinking water should be 20 and $0.01 \mu \mathrm{g} \mathrm{L}^{-1}$ respectively [8].

Although pyrethroids are hazardous to the environment, it is difficult, particularly in tea plantation, to avoid their use as insecticides. Even China and India, which are recognized for producing high-quality tea, rely on synthetic pyrethroids to combat pests and diseases. In Indonesia, the presence of pests and diseases in tea plantation is closely related to climate change and uncontrolled insecticide application, which render tea plantation vulnerable to pests and diseases. Synthetic pyrethroids including bifenthrin, deltamethrin, and permethrin are commonly used insecticides for sustainable tea production.

Furthermore, the risk assessment of synthetic pyrethroids in the tropical soil of a tea plantation has never been performed due to the absence of pyrethroids detected in the soils. Numerous studies to determine and monitor pyrethroids in various plantation and farmland in tropical countries, including Malaysia [12], China [13], India [14], Pakistan [15], the Philippines [16], and Ghana [17] have been conducted. However, there is limited information regarding the presence of pyrethroids in the tropical soil of tea plantation such as in West Bengal, India [18]. In addition, since the great divergence of spatio-temporal can have important implication for the distribution and persistence of pyrethroids, due to the differences in climate and soil types, therefore it is important to obtain the specific data from the local conditions.

Typically, pesticide monitoring involves laborious analytical methods. Many analytical methods for the extraction and analysis of pyrethroids in the soil based on green analytical chemistry have been proposed $[8,15$,
19, 20]. However, the extraction of tropical soil of tea plantation was performed only once [18], and the method was time-consuming, required large volumes (up to $100 \mathrm{~mL}$ ) of organic solvents, such as acetone and dichloromethane, and used large amount of samples, thus generated massive amounts of laboratory waste during analysis. Therefore, the aim of this study was to develop an analytical method to monitor synthetic pyrethroids in a soil of Indonesian tea plantation and to assess their associated ecotoxicological risks. In this study, (i) a method for monitoring pyrethroids in the soil based on green analytical chemistry was developed and validated, (ii) distribution of pyrethroids in the soil of tea plantation was monitored, and (iii) ecotoxicological effects of pyrethroids were assessed by estimating the maximum equilibrium concentration expected in water $\left(\mathrm{ECEW}_{\max }\right)$ value.

\section{Materials and methods \\ Apparatus and chemical}

Synthetic pyrethroids (see Table S1, Additional file 1), were quantified using the Agilent $7890 \mathrm{~B}$ gas chromatography system coupled with a micro-electron capture detector (GC- $\mu \mathrm{ECD})$. Pyrethroids were separated using an HP-5 Agilent column $(30 \mathrm{~m} \times 0.32 \mathrm{~mm} \times 0.25 \mu \mathrm{m})$. Sample injection was performed at the injector temperature of $250{ }^{\circ} \mathrm{C}$ and injection volume of $1 \mu \mathrm{L}$. The oven temperature was initially set at $200{ }^{\circ} \mathrm{C}$ (held for $1 \mathrm{~min}$ ) and then increased to $280{ }^{\circ} \mathrm{C}$ at $20^{\circ} \mathrm{C} \mathrm{min}^{-1}$ (held for 8 min) [11]. The detector temperature was set at $300^{\circ} \mathrm{C}$.

n-hexane and anhydrous sodium sulfate were obtained from Merck, Darmstadt, Germany. Analytical-standard fenvalerate (99.5\%), cypermethrin (99.2\%), permethrin (99.6\%), deltamethrin (99.3\%), and lambda-cyhalothrin (99.5\%) were purchased from Chem Service, West Chester, USA. Individual stock solutions were prepared by diluting each standard pesticide in $\mathrm{n}$-hexane at $100 \mathrm{mg}$ $\mathrm{L}^{-1}$. A mixed stock solution of lambda-cyhalothrin, permethrin, cypermethrin, fenvalerate, and deltamethrin was prepared in $\mathrm{n}$-hexane at $5 \mathrm{mg} \mathrm{L}^{-1}$. Serial dilutions containing a mixture of standard solutions were prepared in $\mathrm{n}$-hexane.

\section{Soil sampling and preparation}

Blank soil for method validation was collected from the nearest area of the tea plantation with no history of pyrethroids (A0) and the soil samples were randomly collected from 11 locations in a tea plantation in the Upper Citarum Watershed (Fig. 1). These 11 sampling locations (A1 - A11) were chosen because of their proximity to the tributary river that will flow into the Citarum River.

Using soil probes, pooled topsoil $(0-20 \mathrm{~cm})$ samples were collected from five sampling points from each 


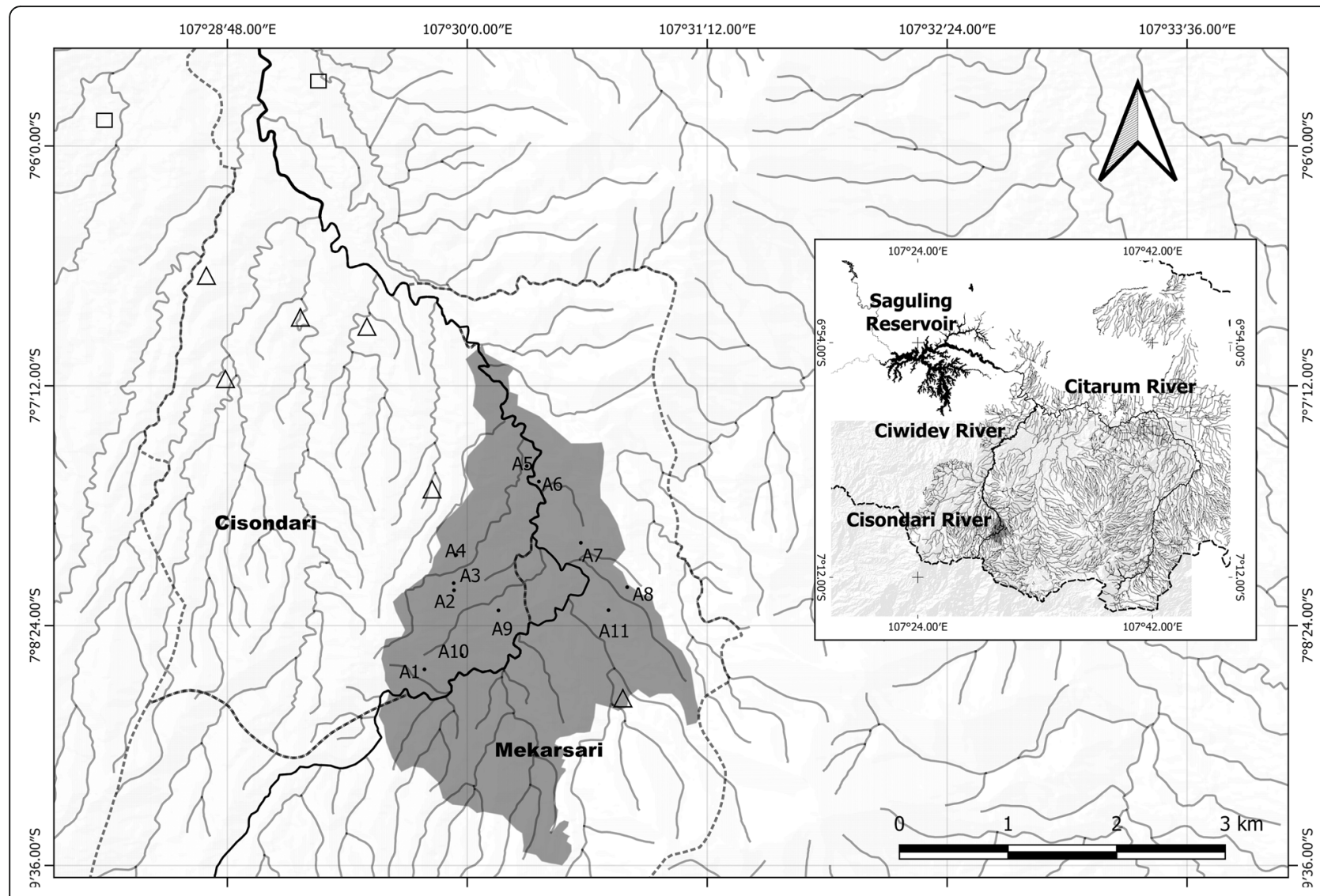

Legends

Administrative boundaries — Cisondari River . Sampling points $\square$ Research area $\square$ Ciwidey tributary $\triangle$ Cisondari tributary

Fig. 1 Soil sampling points in the tea plantation located at Citarum Watershed

location (one each from all corners and one from the center of the field), then mixed thoroughly to make a representative composite sample. In this study, a total 12 soil mixed composite samples were collected from each season, and from each, triplicate sample were made for pyrethroid analysis.

The elevation ranged from $1193 \mathrm{~m}$ at the lowest point to $1411 \mathrm{~m}$ at the highest point. Soil sampling was conducted twice in March and July 2019, representing the wet and dry seasons, respectively, according to the monthly rainfall data for the sampling locations over the last $10 \mathrm{yr}$ obtained from Automatic Weather Stations.

The samples were labeled and transported to the laboratory before physical and chemical examinations. Before extraction, the samples were air-dried at room temperature for $24 \mathrm{~h}$, ground, and sieved through $0.5 \mathrm{~mm}$ mesh (Mesh Number 35). The samples were stored in dark glass jars in a freezer at a temperature below $-4{ }^{\circ} \mathrm{C}$.

\section{Physicochemical properties of soil samples}

Mineral soil was identified via scanning electron microscopy coupled with energy-dispersive X-ray spectrometry (SEM-EDS) and X-ray diffraction (XRD). Soil $\mathrm{pH}$ and conductivity were measured in a 1:5 mixture of soil:distilled water using a $\mathrm{pH}$ meter and conductivity meter (Model TOA DKK MM-60R), respectively, according to Soil Survey Staff [21]. Total organic carbon content was measured using the conventional Walkley-Black method [22].

\section{Pyrethroids extraction and quantification}

Wet weight of soil was used in this experiment. Prior to ultrasound-assisted extraction, each soil sample $(5 \mathrm{~g}$ wet weight) was weighed into a centrifuge tube (50 $\mathrm{mL})$ and $20 \mathrm{~mL}$-hexane was added. The tube was capped and sonicated for $30 \mathrm{~min}$ in an ultrasonic bath and centrifuged at $4000 \mathrm{rpm}$ for $5 \mathrm{~min}$. Extraction was performed twice, and the supernatant (organic layer) was separated. Then, 1-mL aliquot of the combined supernatant was transferred to a column containing a small piece of glass wool and anhydrous sodium sulfate to remove water before being injected into the GC-ECD column. 


\section{Method validation}

Performance of the proposed method was validated by estimating linear range, limit of detection (LoD), limit of quantitation (LoQ), repeatability, and percent recovery of each pyrethroid. Linear range was analyzed by adding (spiked) the soil sample with pyrethroids at seven concentrations, ranging from 0.01 to $0.2 \mathrm{mgg}^{-1}$. LoD and LoQ values were estimated on the basis of signal-tonoise ratios, which were 3 and 10, respectively, for the blank soil sample (no spiked) [23, 24]. Repeatability was calculated as relative standard deviations (RSD) of seven replicates of blank soil added with pyrethroids at $0.1 \mu \mathrm{g}$ $\mathrm{g}^{-1}$. Percent recovery was analyzed by adding the blank soil with pyrethroids at several concentrations (0.01$\left.0.2 \mu \mathrm{gg}^{-1}\right)$. The matrix effect (ME) was analyzed by comparing standard calibration curve and matrix-match calibration curve (as in linear range), using the following Eq. (1) [25]:

$$
M E(\%)=\left[\left(\frac{\text { Slope in matrix }}{\text { Slope in solvent }}\right)-1\right] \times 100
$$

A negative value indicates signal suppression due to the matrices, whereas a positive value indicates signal enhancement. Moreover, a value $<20 \%$ indicates low matrix interference, whereas a value $>20 \%$ indicates high matrix interference [25].

\section{Risk assessment}

In this study, risk assessment for each pyrethroid was performed by estimating its concentration in the soil that might be washed off through leaching and runoff to surface water by calculating the $\mathrm{ECEW}_{\max }\left(\mu \mathrm{L} \mathrm{L}^{-1}\right)$ value using the following Eq. (2) [19]):

$$
E C E W_{\max }=\frac{\text { concentration in soil } l_{\max }}{K_{d}}
$$

ECEW $_{\max }$ represents the probable concentration of each compound in surface water, and $K_{d}\left(\mathrm{~L} \mathrm{~kg}^{-1}\right)$ is the adsorption coefficient of each compound estimated by the following Eq. (3):

$$
K_{d}=K_{O C} x O C
$$

The organic carbon soil partition coefficient $\left(K_{O C}\right)$ was obtained as described previously [26] (Table 1), and the organic carbon content (OC) $\left(\mathrm{g} \mathrm{kg}^{-1}\right)$ was determined through primary assessment of topsoil from each sampling point. The ECEW $\max$ value was compared with $\mathrm{LC}_{50}$ for each aquatic species inhabiting the Upper Citarum River. $\mathrm{LC}_{50}$ values for each species were obtained from secondary data derived from several previous studies as listed in Table 2.

\section{Results and discussion}

\section{Efficiency of the proposed method}

The estimated LoQ using the proposed method was $0.03 \mu \mathrm{gg}^{-1}$ for lambda-cyhalothrin, $0.1 \mu \mathrm{gg}^{-1}$ for per-

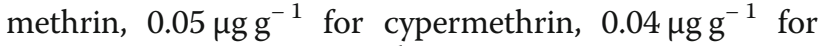
fenvalerate, and $0.02 \mu \mathrm{g} \mathrm{g}^{-1}$ for deltamethrin. The estimated LoD ranged from $0.006 \mu \mathrm{g} \mathrm{g}^{-1}$ for deltamethrin to $0.04 \mathrm{\mu g} \mathrm{g}^{-1}$ for permethrin. The Food and Agriculture Organization, through the Codex Alimentarius, and EU have established the maximum residue levels (MRLs) of all types of pyrethroids in food; however, MRLs of pyrethroids in soil have not been established. The repeatability (\% RSD) of the method was 7.5-13.5\%. Calculated repeatability of the method (\% RSD) was $7.5-13.5 \%$, which was acceptable, being less than $2 / 3$ of the corresponding coefficient variation (CV) in Horwitz's equation. Mean percent recovery of each compound (Table 3) was within the specific range $(80-110 \%)$ determined by Association of Official Analytical Chemists International [40].

Linearity of the method was evaluated by spiked soil samples with pyrethroids standards at seven concentrations $\left(0.01-0.2 \mu \mathrm{g} \mathrm{g}^{-1}\right)$. The coefficient correlations ( $\mathrm{r}$ ) ranged from 0.9963 to 0.9988 (Fig. 2), indicating good linearity. ME of soil on chromatographic signals was also assessed. This was an important aspect of the study because matrix interference is a major problem in the analysis of pesticide residues as it can either enhance or suppress the chromatographic signals, eventually leading to inaccurate recovery estimations [25, 41]. Using Eq.

\begin{tabular}{|c|c|c|c|c|}
\hline Chemical & Log Kow & $\begin{array}{l}\text { Log } \\
\text { KoC }\end{array}$ & Soil aerobic half-life (d) & Soil anaerobil half-life (d) \\
\hline$\lambda$ Cyhalothrin & 7.0 & 5.5 & 42.6 & - \\
\hline Permethrin & 6.1 & 5.4 & 39.5 & 197 \\
\hline Cypermethrin & 6.5 & 5.5 & 27.6 & 55 \\
\hline Fenvalerate $^{a}$ & 6.2 & 5.3 & 100 & 138.2 \\
\hline Deltamethrin & 4.5 & 5.8 & 24.2 & 28.9 \\
\hline
\end{tabular}
(1), ME was estimated by comparing the slope of the

Table 1 Chemical properties of target compound

Source: Laskowski [26]

${ }^{a}$ National Center for Biotechnology Information [27] 
Table 2 Toxicology properties of permethrin and deltamethrin to aquatic organism from different taxa

\begin{tabular}{|c|c|c|c|}
\hline \multirow[t]{2}{*}{ Taxa } & \multirow[t]{2}{*}{ Organism } & \multicolumn{2}{|c|}{ Concentration $\left(\mu \mathrm{g} \mathrm{L}^{-1}\right) /$ Endpoint } \\
\hline & & Permethrin & Deltamethrin \\
\hline Algae & Green algae & $13(96$ h LC L0) [28] & \\
\hline Crustacean & Daphnia magna & $0.08\left(48 h^{L} C_{50}\right)[29]$ & $0.3\left(48 \mathrm{~h} \mathrm{LC}_{50}\right)[30]$ \\
\hline \multirow[t]{7}{*}{ Fish } & Poecilia reticulata (guppy) & 245 (48 h LC 50 ) [31] & $5.1(48 \mathrm{~h} \mathrm{LC}$ 50) [32] \\
\hline & Oreochromis niloticus & & $1.7(48 \mathrm{~h} \mathrm{LC}$ 50) [33] \\
\hline & Oreochromis mossambicus & & $250\left(96 \mathrm{~h} \mathrm{LC}_{50}\right)$ [34] \\
\hline & Clarias gariepinus & & $0.01\left(24 h L_{50}\right)[35]$ \\
\hline & Cyprinus carpio & $35\left(24 h^{2} C_{50}\right)[36]$ & $0.2\left(48 \mathrm{~h} \mathrm{LC} \mathrm{C}_{50}\right)[37]$ \\
\hline & Anabas testudineus & $93(96$ h LC 50 ) [38] & $70(96$ h LC 50 ) [38] \\
\hline & Xiphophorus helleri & & $2.9(96 \mathrm{~h} \mathrm{LC} 50)$ [39] \\
\hline
\end{tabular}

linear equation of standard solutions to the slope of the linear equation of matrix match-calibration with different pyrethroid concentrations ( $\mu \mathrm{gg}^{-1}$ values were converted to equivalent $\mu \mathrm{g} \mathrm{L}^{-1}$ values) (Fig. 2).

Matrix interference for most pyrethroids was determined to be low $(<20 \%)$; for permethrin, matrix interference was determined to be moderate ( $>20 \%)$. Estimation of matrix interference using the proposed analytical method in this study represents how anonymous compounds in the tropical soil of tea plantation interfere with the determination of pyrethroids. In conclusion, all parameters of the proposed method met the acceptance limits, and the method was thus deemed acceptable for the assessment of pyrethroids in real soil samples.

\section{Pyrethroid residues in the soil}

A total of 11 soil samples and one blank sample collected from each sampling location in each season were analyzed for the presence of five pyrethroids (lambdacyhalothrin, permethrin, cypermethrin, fenvalerate, and deltamethrin) using the validated proposed method (Table 3). Less SD values shown in Table 4 indicate the replicability of the method since each sample was analyzed in triplicates. Only permethrin and deltamethrin were detected at most sampling locations (Table 4). The absence of the other pyrethroids assessed on this study was probably due to their low amount of application.
The application of pyrethroids in the study area was dependent on the type of pests and diseases attack during plantation thus some are used more than others. Deltamethrin and permethrin were used dominantly in the study area, with the monthly average area sprayed by the deltamethrin was 140 ha or equal to $63 \%$ from the total area of sampling location. Whereas, only 8 ha or equal to $3 \%$ of the total area of sampling location that was sprayed by the permethrin. The dose for deltamethrin and permethrin were 0.15 and $0.1 \mathrm{~kg} \mathrm{ha}^{-1}$ respectively, and applied only when pests and diseases were present.

The average concentrations of both pyrethroids in soils were higher in the wet season (Table 4). Surprisingly, this finding is contrary to most reported findings. For instance, Delgado-Moreno et al. [4] suggested that pyrethroids were more persistent in the dry season when the precipitation was low. Similarly, previous studies have reported enhanced runoff of herbicides from soil surfaces at high rainfall intensities [42, 43] thus, pyrethroids were rarely detected in wet season.

At most locations, the concentrations of permethrin residues were higher than that of deltamethrin residues. Permethrin concentration ranged from below LoD to $0.36 \mu \mathrm{gg}^{-1}$, whereas deltamethrin concentration ranged from below LoD to $0.12 \mu \mathrm{gg}^{-1}$. However, as MRLs of permethrin and deltamethrin in soil have not been

Table 3 Evaluation of method performance

\begin{tabular}{|c|c|c|c|c|c|}
\hline Parameters & Lambda-Cyhalothrin & Permethrin & Cypermethrin & Fenvalerate & Deltamethrin \\
\hline $\begin{array}{l}\text { Spiked concentration } \\
\left(\mu \mathrm{g} \mathrm{g}^{-1}\right)\end{array}$ & 0.1 & 0.1 & 0.1 & 0.1 & 0.1 \\
\hline Average percent recovery & 96 & 104 & 90 & 96 & 107 \\
\hline RSD, \% & 8.6 & 12.7 & 13.5 & 11.0 & 7.5 \\
\hline $2 / 3 \mathrm{CV}_{\text {Horwitz }}$ & 14.3 & 14.0 & 14.4 & 14.3 & 14.0 \\
\hline Limit of detection $\left(\mu \mathrm{g}^{-1}\right)$ & 0.009 & 0.04 & 0.01 & 0.01 & 0.006 \\
\hline Limit of quantitation $\left(\mu \mathrm{g} \mathrm{g}^{-1}\right)$ & 0.03 & 0.1 & 0.05 & 0.04 & 0.02 \\
\hline Matrix effect (\%) & -1.0 & -29 & -1.6 & -3.1 & -1.3 \\
\hline
\end{tabular}




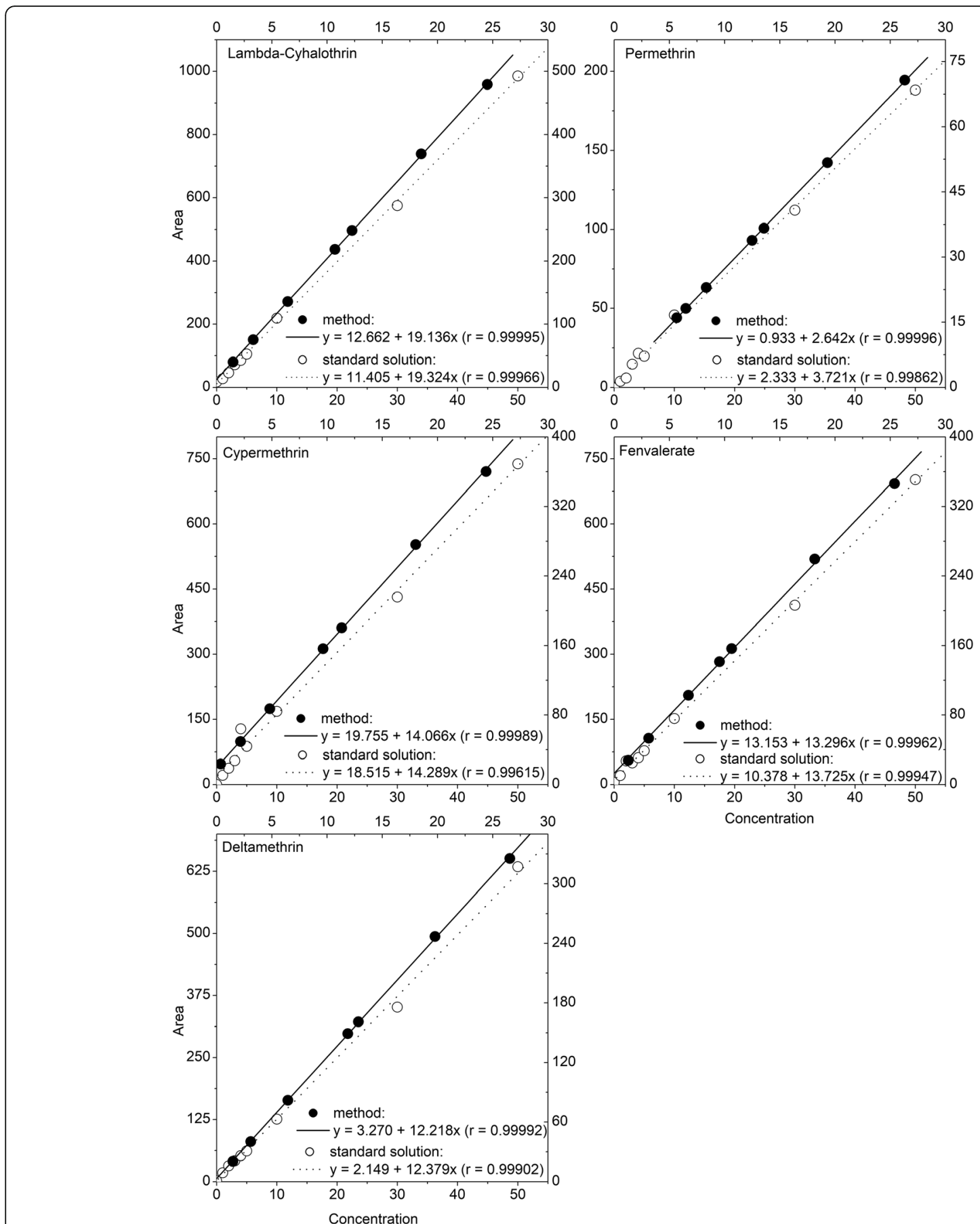

Fig. 2 The linearity of sample solutions (bold) at a range of 0.01 to $0.2 \mathrm{\mu g} \mathrm{g}^{-1}$ and standard solution (light) with pyrethroids concentration range of 0 to $50 \mu \mathrm{g} \mathrm{L}$.

established, this result could not be compared to any regulation.

In this study, the absence of deltamethrin in the dry season might be due to its relatively high rate of photolysis represented by its relatively shorter photolysis and degradation half-life compared to permethrin [26]. In comparison to permethrin, deltamethrin has a shorter photolysis half-life $(34.7 \mathrm{~d})$ and a shorter soil degradation half-life of 24-29 d, whereas, the half-life for photolysis and soil degradation of permethrin was 104 and 39.5-197 d, respectively. Apart from leaching from soil and entering surface water, this pesticide may be lost to the atmosphere because of high temperatures in tropical regions [44]. Although pyrethroids are less volatile than 
Table 4 Concentration $\left(\mu \mathrm{g} \mathrm{g}^{-1}\right.$ ) of pyrethroid in tea plantation soil

\begin{tabular}{|c|c|c|c|c|}
\hline \multirow[t]{3}{*}{ Location } & \multicolumn{2}{|l|}{ Wet season } & \multicolumn{2}{|l|}{ Dry season } \\
\hline & \multicolumn{2}{|c|}{$\overline{\text { Residues }\left(\mu \mathrm{g} \mathrm{g}^{-1}\right) \pm \mathrm{SD}(\mathrm{n}=3)}$} & \multicolumn{2}{|c|}{$\overline{\text { Residues }\left(\mu \mathrm{g} \mathrm{g}^{-1}\right) \pm \mathrm{SD}(n=3)}$} \\
\hline & Permethrin & Deltamethrin & Permethrin & Deltamethrin \\
\hline$\overline{\mathrm{A} 1}$ & $<$ LoQ & $0.09(0.003)$ & $<$ LoQ & $\mathrm{BDL}$ \\
\hline$A 2$ & $0.25(0.020)$ & $0.11(0.006)$ & $<$ LoQ & $\mathrm{BDL}$ \\
\hline A3 & $0.23(0.018)$ & $0.11(0.018)$ & $0.18(0.015)$ & $\mathrm{BDL}$ \\
\hline A4 & $<$ LoQ & $0.09(0.007)$ & $<$ LoQ & $\mathrm{BDL}$ \\
\hline A5 & $0.18(0.018)$ & $0.09(0.012)$ & $0.16(0.018)$ & $\mathrm{BDL}$ \\
\hline A6 & $0.23(0.030)$ & $0.10(0.002)$ & $0.32(0.042)$ & $\mathrm{BDL}$ \\
\hline A7 & $0.28(0.028)$ & $0.10(0.006)$ & $0.23(0.015)$ & $\mathrm{BDL}$ \\
\hline A8 & $0.27(0.031)$ & $0.10(0.003)$ & $0.14(0.018)$ & $\mathrm{BDL}$ \\
\hline A9 & $\mathrm{BDL}$ & $0.12(0.017)$ & $0.15(0.015)$ & $\mathrm{BDL}$ \\
\hline $\mathrm{A} 10$ & $0.21(0.044)$ & $0.12(0.020)$ & $0.22(0.023)$ & $\mathrm{BDL}$ \\
\hline $\mathrm{A} 11$ & $0.36(0.031)$ & $0.12(0.025)$ & $<\mathrm{LoQ}$ & $\mathrm{BDL}$ \\
\hline
\end{tabular}

$B D L$ Below detection limit

other pesticides [45], deltamethrin has a shorter photolysis half-life and shorter degradation half-life than other pyrethroids [26]. This may explain the lower concentrations of deltamethrin in the wet season and its complete below the detection limit at all sampling locations in the dry season.

The lower intensity of application of both pyrethroids in the dry season might also contribute to the absence of deltamethrin. Whereas for permethrin, the lowest concentration $(<\mathrm{LoQ})$ of this compound at several location sampling during the dry season such as A1, A2, A4, and A11 (see Table 4) might be due to insignificant area of the sampling location that was sprayed by the permethrin during the dry season. The intensity of pyrethroids application in the sampling locations examined depended on the intensity of rainfall and the occurrence of attacks by pests and diseases. The rainfall intensity was up to $328.9 \mathrm{~mm} \mathrm{month}^{-1}$ in the wet season and $110.3 \mathrm{~mm} \mathrm{month}^{-1}$ in the dry season with more frequent spraying in the wet season.

Conversely, during the wet season, almost all of the sampling locations were sprayed by permethrin except for the location where the pests and diseases did not exist such as at A1, A4, and A9. For instance, only half of $\mathrm{A} 1$ and one-third of $\mathrm{A} 4$ were sprayed by permethrin. However, due to limited record of pesticide application this assumption cannot be concluded and further research is needed.

The fate and distribution of pyrethroids in the soil, that is whether they persist, degrade, or are washed off through leaching, depend on soil characteristics, climate, and soil microbiome [12, 16, 20,46]. Soil properties impact on pyrethroid persistence in many ways. Typically, pyrethroids are more persistent in soils with a lower $\mathrm{pH}$.
Deltamethrin degradation is higher at a $\mathrm{pH}$ of 3 [12], and higher $\mathrm{pH}(\mathrm{pH}=9)$ might hydrolyze permethrin [26]. In this study, the sampled soil showed similar pHs in both seasons, ranging from $\mathrm{pH} 5.2-6$ (Table 5). Permethrin and deltamethrin are relatively stable at this range and their hydrolyzation is unlikely [26].

Furthermore, the hydrophobicity of each pyrethroid, as represented by its octanol/water partition coefficient $\left(\mathrm{K}_{\mathrm{Ow}}\right)$ and water solubility, affects its mobility. As permethrin has a higher $\mathrm{K}_{\mathrm{OW}}$ and a lower soil adsorption coefficient than deltamethrin [26], its concentration in soil was expected to be lower than that of deltamethrin. Surprisingly, in this study, permethrin concentrations were higher than deltamethrin. To explain these phenomena, the sampled soil was characterized through SEM-EDS and XRD, which revealed the presence of several elements such as $\mathrm{Si}, \mathrm{Ca}, \mathrm{Al}, \mathrm{K}, \mathrm{Fe}$, and $\mathrm{O}$ and major soil minerals such as quartz, anorthite, microcline, carborundum, magnetite, zeolite, and potassium calcium silicate (see Data S1 and S2, Additional file 1). These soil minerals in combination with high total organic carbon content increase the adsorptivity of soil particles for pyrethroids [47].

In the studied region, the total organic carbon content of the soil was relatively high, ranging from 30.4 to 62.3 $\mathrm{g} \mathrm{kg}^{-1}$ (Table 5), rendering permethrin was more persistent in the soil. Conversely, deltamethrin is less hydrophobic than permethrin (lower $\mathrm{K}_{\mathrm{OW}}$ and higher $\mathrm{K}_{\mathrm{OC}}$; Table 1). The higher content of organic carbon in soil will lower the degradation rate of deltamethrin [46], and the low adsorption of deltamethrin on soil particles will eventually make deltamethrin washed off through leaching.

So far, there has been only one study exploring the presence of pyrethroids in the soil of tea plantation, e.g.,

Table 5 Soil characteristics

\begin{tabular}{|c|c|c|c|c|c|c|c|}
\hline \multirow[t]{2}{*}{$\begin{array}{l}\text { Sampling } \\
\text { location }\end{array}$} & \multicolumn{2}{|l|}{$\mathrm{pH}$} & \multicolumn{2}{|c|}{$\begin{array}{l}\text { Conductivity } \\
\left(\mu \mathrm{sm}^{-1}\right) \\
\end{array}$} & \multicolumn{2}{|c|}{$\begin{array}{l}\text { Soil water content } \\
(\%)\end{array}$} & \multirow{2}{*}{$\begin{array}{l}\text { Average } \\
\text { total } \\
\text { organic } \\
\text { carbon } \\
\left(\mathrm{g} \mathrm{kg}^{-1}\right)\end{array}$} \\
\hline & Dry & Wet & Dry & Wet & Dry & Wet & \\
\hline$\overline{\mathrm{A} 1}$ & 5.51 & 6.01 & 38.6 & 51 & 33.0 & 43.2 & 62.3 \\
\hline $\mathrm{A} 2$ & 5.48 & 5.65 & 57.3 & 21.9 & 25.2 & 42.9 & 56.8 \\
\hline $\mathrm{A} 3$ & 5.43 & 5.43 & 55.9 & 17.9 & 30.7 & 43.1 & 54.7 \\
\hline A4 & 5.36 & 5.57 & 26.3 & 16.2 & 30.6 & 42.6 & 59.9 \\
\hline A5 & 5.54 & 5.45 & 31.5 & 28.7 & 25.2 & 34.8 & 32.2 \\
\hline A6 & 5.46 & 5.71 & 52.3 & 38.2 & 22.1 & 34.6 & 30.8 \\
\hline A7 & 5.22 & 5.43 & 56.1 & 20 & 29.5 & 40.2 & 59.5 \\
\hline A8 & 5.81 & 5.54 & 38.7 & 54.8 & 27.5 & 43.5 & 54.4 \\
\hline A9 & 5.42 & 5.9 & 51.4 & 12.9 & 32.6 & 42.7 & 59.5 \\
\hline $\mathrm{A} 10$ & 5.47 & 5.68 & 41.8 & 40.6 & 29.1 & 43.4 & 59.5 \\
\hline $\mathrm{A} 11$ & 5.23 & 5.09 & 44.2 & 43.5 & 24.8 & 43.8 & 30.4 \\
\hline
\end{tabular}


in India [18], but unfortunately, none of synthetic pyrethroids were detected in the soils of that region, therefore, pyrethroid levels detected in the present study were compared with those in other studies that successfully detected pyrethroid residues in soils from various tropical ecosystems. In previous studies conducted in different types of tropical plantation [13, 15-17], deltamethrin was detected in cotton/wheat soil $\left(6 \times 10^{-5}-1.8 \mu \mathrm{gg}^{-1}\right)$, chestnut soil $(<$ LoD $\left.-0.03 \mu \mathrm{g} \mathrm{g}^{-1}\right)$, walnut soil $\left(<\mathrm{LoD}-0.02 \mu \mathrm{g} \mathrm{g}^{-1}\right)$, pinenut soil $\left(<\mathrm{LoD}-0.005 \mu \mathrm{gg}^{-1}\right)$, cabbage soil $(0.007-$ $\left.0.008 \mu \mathrm{g} \mathrm{g}^{-1}\right)$, and cacao soil $\left(0.04 \mu \mathrm{gg}^{-1}\right)$. Meanwhile, permethrin has never been detected in plantation soils but it was detected in rivers near the plantation $\left(<100 \mu \mathrm{g} \mathrm{L}^{-1}\right)$ [6].

\section{Risk assessment}

The monitoring of synthetic pyrethroids in the soil of tropical tea plantation, particularly in the Citarum Watershed, Indonesia, is challenging in the light of the conservation and restoration program for the Citarum River proposed by the government. The purpose of this assessment was to determine the toxicity of pyrethroids retained in the soil of tea plantation leaching to surface water. Introduction of pyrethroids into surface water through runoff and leaching might negatively affect aquatic organisms. Using mean total organic carbon content and mean concentration of each pyrethroid in the sampled soil, the ECEW $\max$ values for permethrin and deltamethrin in surface water in the wet season were 0.024 and $0.004 \mathrm{\mu g} \mathrm{L}^{-1}$, respectively. Meanwhile, the $\mathrm{ECEW}_{\max }$ value for permethrin in the dry season was $0.019 \mu \mathrm{g} \mathrm{L}^{-1}$. This pattern was similar to that observed in a previous study in the Mekong Delta by Toan et al. [5], that were frequently detected high concentrations of pyrethroids in surface water following heavy rainfall.

Although pyrethroids are considered to be slightly toxic to mammals and birds, they exhibit high acute and chronic toxicity in aquatic organisms [10]. Several studies have demonstrated that the Upper Citarum River is home to aquatic organisms from the lowest to the highest trophic levels, including algae of the family Bacillariophyceae, planktonic crustaceans such as Daphnia sp., and 10 species of fish [48-50]. Toxicological properties of permethrin and deltamethrin in some of these species are presented in Table 2.

Notably, the ECEW $\max$ values for permethrin and deltamethrin were below the toxicity threshold for each aquatic organism. The $\mathrm{LC}_{50}$ values for fish exposed to deltamethrin and permethrin were higher than the $\mathrm{ECEW}_{\max }$ values estimated in this study (Table 2); thus, no toxic effects were expected. Our estimation revealed that the maximum threshold for permethrin concentration retained in the soil of tea plantation representing the safe limit for aquatic organisms inhabiting in the Upper Citarum River was $136 \mu \mathrm{g} \mathrm{g}^{-1}$ for algae, $0.84 \mu \mathrm{gg}^{-1}$ for Daphnia sp., and $366 \mu \mathrm{g} \mathrm{g}^{-1}$ for fish. Meanwhile, the maximum threshold for deltamethrin concentration representing the safe limit was $8.0 \mu \mathrm{gg}^{-1}$ for Daphnia sp. and $0.27 \mu \mathrm{gg}^{-1}$ for fish. The half-life of permethrin in soil, under either aerobic or anaerobic conditions, is relatively short, ranging from 39.5 to $197 \mathrm{~d}$ (Table 1) and it is even shorter for deltamethrin. Therefore, as long as there is no significant leaching or runoff caused by heavy rainfall, both permethrin and deltamethrin are expected to either persist or naturally degrade in soil. Due to the strong affinity of permethrin for soil particles and solid surfaces and the high bioavailability of deltamethrin, further research into pyrethroid remediation using indigenous microbes in the tropical soils of tea plantation is highly recommended.

\section{Conclusions}

The developed method for detecting and analyzing pyrethroids in tropical soils of a tea plantation was validated and deemed suitable for monitoring pyrethroid in soil during wet and dry seasons. Contrast to most reported findings, permethrin was more persist than deltamethrin both in wet and dry seasons due to the combination of several elements exist in the soil and high total organic carbon content. Risk assessment of the presence of permethrin and deltamethrin in surface water by estimating the ECEW ${ }_{\max }$ values showed that each compound was present at a concentration lower than the $\mathrm{LC}_{50}$ value for any aquatic organism inhabiting the Upper Citarum River.

\section{Supplementary information}

Supplementary information accompanies this paper at https://doi.org/10. 1186/s42834-020-00055-7.

Additional file 1. Pyrethroid properties and soil characterization. Table S1. Properties of pyrethroids. Data S1. Soil characterization by scanning electron microscopy coupled with energy-dispersive X-ray spectrometry (SEM-EDS). Data S2. Soil characterization by X-ray diffraction (XRD)

\section{Acknowledgements}

The authors wish to thank Puput Febrianto for his help for map preparation.

\section{Authors' contributions}

Miranti Ariyani (MA) conducted the research, interpreted the data and prepared the manuscript; Mariska Margaret Pitoi (MMP) help interpreted the data and critically reviewed the manuscript; Tiny Agustini Koesmawati (TAK) helped critically reviewed the manuscript.; Hilman Maulana (HM) provide the guidance for tea plantation and helped provide the soil samples; Een Sri Endah (ESE) prepared the assessment for soil characterization and its interpretation. Retno Yusiasih (RY) helped validate the method for analysis. The authors read and approved the final manuscript.

\section{Funding}

This research was supported by the Ministry of Research Technology and Higher Education, Indonesia under INSINAS 2019 Research Grant Programme [contract number 047/P/RPL-LIPI/INSINAS-1/II/2019] and Indonesian Institute of Sciences under DIPA 2019 Research Grant. 


\section{Availability of data and materials}

All the data are provided in the manuscript and additional file.

\section{Competing interests}

The authors declare they have no competing interests.

\section{Author details}

'Research Unit for Clean Technology, Indonesian Institute of Sciences, Bandung 40135, Indonesia. ${ }^{2}$ Bakti Asih Higher Education for Analyst, Bandung 40192, Indonesia. ${ }^{3}$ Research Institute for Tea and Cinchona, Bandung 40362, Indonesia.

\section{Received: 23 January 2020 Accepted: 15 June 2020}

Published online: 01 July 2020

\section{References}

1. Gajendiran A, Abraham J. An overview of pyrethroid insecticides. Front Biol. 2018:13:79-90.

2. Tang WX, Wang D, Wang JQ, Wu ZW, Li LY, Huang ML, et al. Pyrethroid pesticide residues in the global environment: an overview. Chemosphere. 2018;191:990-1007.

3. Geissen V, Mol H, Klumpp E, Umlauf G, Nadal M, van der Ploeg M, et al. Emerging pollutants in the environment: a challenge for water resource management. Int Soil Water Conse. 2015:3:57-65.

4. Delgado-Moreno L, Lin K, Veiga-Nascimento R, Gan J. Occurrence and toxicity of three classes of insecticides in water and sediment in two southern California coastal watersheds. J Agric Food Chem. 2011;59:9448-56.

5. Toan PV, Sebesvari Z, Blasing M, Rosendahl I, Renaud FG. Pesticide management and their residues in sediments and surface and drinking water in the Mekong Delta, Vietnam. Sci Total Environ. 2013:452:28-39.

6. Zheng SL, Chen B, Qiu XY, Chen M, Ma ZY, Yu XG. Distribution and risk assessment of 82 pesticides in Jiulong River and estuary in South China. Chemosphere. 2016;144:1177-92.

7. Oros DR, Werner I. Pyrethroid insecticides: an analysis of use patterns, distributions, potential toxicity and fate in the Sacramento-san Joaquin Delta and Central Valley. Oakland: San Francisco Estuary Institute; 2005.

8. Albaseer SS, Rao RN, Swamy YV, Mukkanti K. An overview of sample preparation and extraction of synthetic pyrethroids from water, sediment and soil. J Chromatogr A. 2010;1217:5537-54.

9. Amweg EL, Weston DP, Ureda NM. Use and toxicity of pyrethroid pesticides in the Central Valley, California, USA. Environ Toxicol Chem. 2005:24:966-72.

10. Li HZ, Cheng F, Wei YL, Lydy MJ, You J. Global occurrence of pyrethroid insecticides in sediment and the associated toxicological effects on benthic invertebrates: an overview. J Hazard Mater. 2017:324:258-71.

11. Pitoi MM, Ariyani M, Koesmawati TA, Yusiasih R. Pyrethroids residues analysis in Indonesian commercial tea by GC-ECD. Aims Agric Food. 2019:4:447-57.

12. Ismail BS, Mazlinda M, Tayeb MA. The persistence of deltamethrin in Malaysian agricultural soils. Sains Malays. 2015:44:83-9.

13. Han $Y X$, Mo RH, Yuan XY, Zhong DL, Tang FB, Ye CF, et al. Pesticide residues in nut-planted soils of China and their relationship between nut/soil. Chemosphere. 2017;180:42-7.

14. Murugan AV, Swarnam TP, Gnanasambandan S. Status and effect of pesticide residues in soils under different land uses of Andaman Islands, India. Environ Monit Assess. 2013;185:8135-45.

15. Rafique N, Tariq SR, Ahmed D. Monitoring and distribution patterns of pesticide residues in soil from cotton/wheat fields of Pakistan. Environ Monit Assess. 2016;188:695.

16. Calinawan A, Mendoza CS, Adarna L. Preliminary study on deltamethrin residues in cabbage, soil and water from Dalaguete, Cebu, Philippines. KIMIKA. 2016:27:1-11.

17. Fosu-Mensah BY, Okoffo ED, Mensah M. Synthetic pyrethroids pesticide residues in soils and drinking water sources from cocoa farms in Ghana. Environ Pollut. 2016;5:60-72.

18. Bishnu A, Chakrabarti K, Chakraborty A, Saha T. Pesticide residue level in tea ecosystems of hill and Dooars regions of West Bengal, India. Environ Monit Assess. 2009:149:457-64.

19. Aznar R, Moreno-Ramon H, Albero B, Sanchez-Brunete C, Tadeo JL. Spatiotemporal distribution of pyrethroids in soil in Mediterranean paddy fields. $J$ Soil Sediment. 2017;17:1503-13

20. Braganca I, Lemos PC, Delerue-Matos C, Domingues VF. Assessment of pyrethroid pesticides in topsoils in northern Portugal. Water Air Soil Pollut. 2019;230:166.
21. Soil Survey Staff. Soil survey field and laboratory methods manual. Soil survey investigations report no. 51, version 2.0. Lincoln: US Department of Agriculture, Natural Resources Conservation Service; 2014

22. APHA. Standard methods for the examination of water and wastewater. 21st ed. Washington, DC: American Public Health Association; 2005.

23. Paramasivam M, Chandrasekaran S. Persistence behaviour of deltamethrin on tea and its transfer from processed tea to infusion. Chemosphere. 2014; 111:291-5.

24. Pastor-Belda M, Navarro-Jimenez T, Garrido I, Vinas P, Campillo N, Fenoll J, et al. Magnetic solid-phase extraction or dispersive liquid-liquid microextraction for pyrethroid determination in environmental samples. J Sep Sci. 2018;41:2565-75.

25. Lozowicka B, Rutkowska E, Jankowska M. Influence of QuEChERS modifications on recovery and matrix effect during the multi-residue pesticide analysis in soil by GC/MS/MS and GC/ECD/NPD. Environ Sci Pollut R. 2017;24:7124-38.

26. Laskowski DA. Physical and chemical properties of pyrethroids. In: Ware GW editor. Reviews of environmental contamination and toxicology. Vol. 174. New York: Springer; 2002. p. 49-170.

27. NCBI. PubChem database. Bethesda: National Center for Biotechnology Information; 2020.

28. DeLorenzo ME, Fulton MH. Comparative risk assessment of permethrin, chlorothalonil, and diuron to coastal aquatic species. Mar Pollut Bull. 2012; 64:1291-9.

29. Werner I, Moran K. Effects of pyrethroid insecticides on aquatic organisms. In: Gan J, Spurlock F, Hendley P, Weston DP, editors. Synthetic pyrethroids Washington, DC: American Chemical Society; 2008. p. 310-34.

30. Toumi H, Boumaiza M, Millet M, Radetski CM, Felten V, Fouque C, et al. Effects of deltamethrin (pyrethroid insecticide) on growth, reproduction, embryonic development and sex differentiation in two strains of Daphnia magna (Crustacea, Cladocera). Sci Total Environ. 2013;458:47-53.

31. Baser S, Erkoc F, Selvi M, Kocak O. Investigation of acute toxicity of permethrin on guppies Poecilia reticulata. Chemosphere. 2003;51:469-74.

32. Viran $\mathrm{R}$, Erkoc FU, Polat $H$, Kocak O. Investigation of acute toxicity of deltamethrin on guppies (Poecilia reticulata). Ecotox Environ Safe. 2003; 55:82-5.

33. Kan Y, Cengiz El, Ugurlu P, Yanar M. The protective role of vitamin E on gill and liver tissue histopathology and micronucleus frequencies in peripheral erythrocytes of Oreochromis niloticus exposed to deltamethrin. Environ Toxicol Phar. 2012;34:170-9.

34. Vijayavel K, Balasubramanian MP. Interaction of potash and decis in the ecophysiology of a freshwater fish Oreochromis mossambicus. Ecotox Environ Safe. 2007:66:154-8.

35. Datta M, Kaviraj A. Acute toxicity of the synthetic pyrethroid deltamethrin to freshwater catfish Clarias gariepinus. B Environ Contam Tox. 2003:70:296-9.

36. Sial IM, Kazmi MA, Kazmi QB, Naqvi SNH. Toxicity of biosal (phytopesticide) and permethrin (pyrethroid) against common carp, Cyprinus carpio. Pak J Zool. 2009;41:235-8.

37. Koprucu K, Aydin R. The toxic effects of pyrethroid deltamethrin on the common carp (Cyprinus carpio L.) embryos and larvae. Pestic Biochem Phys. 2004;80:47-53.

38. Maisnam SD, Abhik G. Acute toxicity of deltamethrin and permethrin and their sublethal effects on growth and feeding in Anabas testudineus. Int Res J Biol Sci. 2014;3:18-22.

39. Khalili M, Khaleghi SR, Hedayati A. Acute toxicity test of two pesticides diazinon and deltamethrin, on swordtail fish (Xiphophorus helleri). Glob Vet. 2012:8:541-5.

40. AOAC International. Appendix F: guidelines for standard method performance requirements. Rockville: Association of Official Analytical Chemists International; 2016.

41. Kruve A, Kunnapas A, Herodes K, Leito I. Matrix effects in pesticide multiresidue analysis by liquid chromatography-mass spectrometry. J Chromatogr A. 2008;1187:58-66.

42. Muller K, Trolove M, James TK, Rahman A. Herbicide loss in runoff: effects of herbicide properties, slope, and rainfall intensity. Aust J Soil Res. 2004;42:17-27.

43. Jiang WY, Haver D, Rust M, Gan J. Runoff of pyrethroid insecticides from concrete surfaces following simulated and natural rainfalls. Water Res. 2012; 46:645-52.

44. Laabs V, Amelung W, Pinto AA, Wantzen M, da Silva CJ, Zech W. Pesticides in surface water, sediment, and rainfall of the northeastern Pantanal basin, Brazil. J Environ Qual. 2002;31:1636-48. 
45. Bennett ER, Moore MT, Cooper CM, Smith S, Shields FD, Drouillard KG, et al. Vegetated agricultural drainage ditches for the mitigation of pyrethroidassociated runoff. Environ Toxicol Chem. 2005;24:2121-7.

46. Cycon M, Zmijowska A, Piotrowska-Seget Z. Enhancement of deltamethrin degradation by soil bioaugmentation with two different strains of Serratia marcescens. Int J Environ Sci Te. 2014;11:1305-16.

47. Oudou HC, Hansen HCB. Sorption of lambda-cyhalothrin, cypermethrin, deltamethrin and fenvalerate to quartz, corundum, kaolinite and montmorillonite. Chemosphere. 2002;49:1285-94.

48. Putra AW, Hasan Z. Plankton community structure in the upper Citarum River, West Java. J Fish. 2012:3:1-13 [in Indonesian].

49. Sunardi KK, Husodo T, Malini DM, Astari AJ. Distribution of fish in the upper Citarum River: an adaptive response to physico-chemical properties. HAYATI J Biosci. 2012;19:191-6.

50. Muntalif BS, Chasanah N, Faza MF. Relationship population density of aquatic sediment macrozoobenthos to river water quality parameters: case study of upstream Citarum River in Bandung regency. J Environ Sci Eng. 2016;5:117-25

\section{Publisher's Note}

Springer Nature remains neutral with regard to jurisdictional claims in published maps and institutional affiliations.

Ready to submit your research? Choose BMC and benefit from:

- fast, convenient online submission

- thorough peer review by experienced researchers in your field

- rapid publication on acceptance

- support for research data, including large and complex data types

- gold Open Access which fosters wider collaboration and increased citations

- maximum visibility for your research: over $100 \mathrm{M}$ website views per year

At BMC, research is always in progress.

Learn more biomedcentral.com/submissions 